\title{
Efficacy and safety of immunosuppressive therapy in the treatment of seronegative hepatitis associated aplastic anemia
}

This article was published in the following Dove Press journal:

Drug Design, Development and Therapy

9 September 2014

Number of times this article has been viewed

\author{
Hai-Fei Chen* \\ Bin-Xian Xu \\ Hong-Shi Shen* \\ Zheng-Yang Li \\ Ling-Juan Jin \\ Jie-Qing Tang \\ Jing Wang \\ Jing-Jing Zhu \\ Long-Mei Qin \\ Qing-Ya Cui \\ Yong-Ya Ren \\ Tian-Qin Wu
}

Department of Hematology, 100th Hospital of People's Liberation Army, Suzhou, Jiangsu province, The People's Republic of China

*These authors have contributed equally to this paper
Correspondence: Tian-Qin Wu Department of Hematology, 100th Hospital of People's Liberation Army, Wuqueqiao Road 53\#, Suzhou City, Jiangsu Province, The People's Republic of China

Tel +8605I26506 354I

Email chhfI224@I63.com
Objective: To investigate the clinical characteristics of seronegative hepatitis-associated aplastic anemia (AA) (SNHAA) and hepatitis B virus (HBV) infection complicating AA (HBVAA), and thereby compare the efficacy of immunosuppressive therapy (IST).

Methods: An analysis was conducted on the clinical data of ten patients with SNHAA out of 332 cases of AA from our center at AA diagnosis, and on the efficacy of IST. This was compared to 22 cases of HBVAA at AA onset as well as the associated IST outcomes.

Results: Nine patients with SNHAA developed severe aplastic anemia, with a median age of 18 years. After IST, six $(60 \%)$ of the SNHAA patients achieved complete remission and two achieved partial remission. The patients with HBVAA had a total response rate of $82.3 \%$. The disease recurred in two HBVAA patients. No statistically significant differences were observed in response rate, mortality, and recurrence rate between both groups. As compared with HBVAA, patients with SNHAA had a shorter interval from the acute episode of hepatitis to AA onset ( 4 months versus 92 months, $P=0.00$ ), a quicker response to IST ( 2.5 months versus 4.5 months, $P=0.018)$, a lower proportion of bone marrow hematopoietic tissues $(20.6 \%$ versus $23.6 \%$, $P=0.03)$, and lower white blood cell and absolute neutrophil count $\left(0.8 \times 10^{9} / \mathrm{L}\right.$ versus $1.23 \times 10^{9} / \mathrm{L}$ and $0.26 \times 10^{9} / \mathrm{L}$ versus $0.58 \times 10^{9} / \mathrm{L}, P=0.026$ and $P=0.0009$, respectively). No significant liver damage or hepatitis B fulminant infection was observed in either group during the follow-up. Conclusion: The prevalence of SNHAA is $3.01 \%$. SNHAA often presents as severe AA and responds to IST quickly. Neither hepatitis prior to AA nor AA complicating HBV infection have been shown to influence the early efficacy of IST and adverse events, and HBV may not be the causative agent of AA.

Keywords: hepatitis-associated aplastic anemia, hepatitis B infection, liver injury

\section{Introduction}

Hepatitis-associated aplastic anemia (HAA) is defined as aplastic anemia (AA) after the occurrence of acute hepatitis, and, accordingly, it is known as posthepatitic AA. ${ }^{1}$ This disease has an abrupt onset, and the bone marrow failure and pancytopenia often occurs within several months to 1 year after an acute episode of hepatitis. The disease deteriorates rapidly at the time of AA onset and has a high mortality. ${ }^{1,2}$ The cause of hepatitis remains unknown in HAA patients. Most study results suggest non-A-E hepatitis in such patients. ${ }^{1,2}$ The People's Republic of China has a high epidemiology of hepatitis B virus (HBV) infection, ${ }^{3,4}$ but it is not known whether HBV infection correlates to the occurrence of AA. Moreover, the efficacy of immunosuppressive therapy (IST) in AA patients coinfected with HBV is not certain, as AA patients who receive administrations of IST may suffer the worsening of HBV infection or even fulminant viral hepatitis. To encourage a fuller understanding of the disease, we conducted a 
clinical study on patients with seronegative HAA (SNHAA) and HBV infection complicating AA (HBVAA) who had been treated at our center over the past few years.

\section{Patients and methods}

\section{Study subjects}

Thirty-two patients with SNHAA and HBVAA hospitalized at our hematologic center from January 2002 to March 2013, accounting for $9.63 \%$ (32/332) of the total number of AA cases during the same period, were divided into the following two groups. The SNHAA group comprised ten cases, accounting for 3.01\% (10/332), including eight males and two females; a median age of 18 (6-36) years; with non-A-G hepatitis in serologic markers or DNA/RNA by the polymerase chain reaction test; and Epstein-Barr virus (EBV), cytomegalovirus (CMV), human immunodeficiency virus (HIV), and human parvovirus B19 (HPV B19) also being tested as negative. The HBVAA group comprised 22 patients, accounting for $6.62 \%$ (22/332) of the total patients with AA during the same period; it included 14 males and eight females, with a median age of 28 (17-57) years. Nineteen patients in the HBVAA group had HBV DNA ranging from $1 \times 10^{3}$ to $8 \times 10^{8}$ copies $/ \mathrm{mL}$ (reference value $<500$ copies $/ \mathrm{mL}$ ), and three cases had HBV DNA below the detection threshold but with positive markers such as hepatitis B surface antigen ( $\mathrm{HBsAg})$.

\section{Methods}

\section{Test methods}

Venous blood samples were for standard diagnostic serologies: $\mathrm{HBsAg}$, $\mathrm{HBs} A b$, and $\mathrm{HBcAb}$. Test results were used to categorized patients in serological profiles: 1) infection (HBsAg positive, hepatitis B surface antibody [HbsAb] negative, hepatitis $\mathrm{B}$ c antibody [HbcAb] positive); 2) immune due to natural infection (HBsAg negative, $\mathrm{HbsAb}$ positive, $\mathrm{HbcAb}$ positive); 3) susceptible ( $\mathrm{HBsAg}$ negative, $\mathrm{HbsAb}$ negative, $\mathrm{HbcAb}$ negative); 4) Immune due to vaccination (HBsAg negative, HbsAb positive, $\mathrm{HbcAb}$ negative); and 5) other/further testing required ( $\mathrm{HBsAg}$ negative, $\mathrm{HbsAb}$ negative, $\mathrm{HbcAb}$ positive). The processing laboratory was instructed to retain blood for all individuals to subsequently verify HBsAg positive samples to hepatitis B e antibody, hepatitis $\mathrm{B}$ e antigen, and HBV DNA quantitative fluorescence polymerase chain reaction $\left(\mathrm{COBAS}^{\circledR}\right.$ TaqMan $^{\circledR}$; Hoffman-La Roche Ltd., Basel, Switzerland. LOQ=29 IU/mL) tests. Other viral hepatitis - including anti-hepatitis C virus IgM, anti-hepatitis D virus IgM or IgG, and anti-hepatitis E virus IgM - were tested for in all the patients by enzyme-linked immunosorbent assay. Meanwhile CMV, HIV, HPV B19, and EBV were detected by routine clinical methods.

\section{Treatments and follow-ups \\ IST}

As soon as a patient was diagnosed with severe AA (SAA) with no severe infection, he/she was given anti-human $\mathrm{T}$ lymphocyte porcine immunoglobulin (ALG) in combination with cyclosporine A (CsA) (ALG at a dose of 20-30 mg/kg/d) for 5 consecutive days (day 1-5); the patient with no significant infection after administration of ALG was intravenously given CsA $5 \mathrm{mg} / \mathrm{kg} / \mathrm{d}$ at the $3 \mathrm{rd}$ week (day 21) to maintain for 24 hours per day for 10 consecutive days, and then switched to $3-8 \mathrm{mg} / \mathrm{kg} / \mathrm{d}$ divided into two doses for oral treatment. After 5 days, the CsA concentration was measured, its trough concentration was maintained at $200-400 \mu \mathrm{g} / \mathrm{mL}$ within the first 3 months, and the dosage was gradually reduced when the maximum effect was achieved. The total course of treatment with CsA was 1-2 years. The patients treated with ALG were conventionally given corticosteroids (oral prednisone $1 \mathrm{mg} / \mathrm{kg} / \mathrm{d}$ or equivalent infusion of dexamethasone for day 1-14; then treatment was tapered off from day 15, and ceased at the end of 3rd or 4th week), antihistamines, calcium, potassium, and either proton pump inhibitors for adult patients or famotidine for child patients as an adjuvant therapy. Once or twice each month, the patients were monitored for liver function, kidney function, electrolytes, and CsA concentration. Depending on the absolute neutrophil count and infection in the patient, recombinant human granulocyte colony-stimulating factor or recombinant human granulocyte-monocyte colony-stimulating factor was administered. The patients were carefully monitored for any infection and were given appropriate antibiotics in the event of infection. The patients were given transfusions of blood components as necessary in order to maintain hemoglobin $\geq 60 \mathrm{~g} / \mathrm{L}$ as well as to avoid the tendency toward serious clinical bleeding.

\section{Treatment with CsA alone}

One patient in the SNHAA group and five patients in the HBVAA group received the treatment with CsA alone. The other treatments and surveillance were exactly the same as in the case of enhanced immunosuppressive therapy except for ALG, corticosteroids, and antihistamines.

\section{Antiviral treatment}

In the HBVAA group, patients with HBV DNA $>10^{4}$ copies/ $\mathrm{mL}$ were given conventional antiviral therapy at 3-5 days 
before receiving immunosuppressive therapy. Four patients received lamivudine for 3 months, and nine patients used entecavir for 3 months.

\section{Diagnostic criteria, classification criteria, and efficacy criteria}

The criteria used for the diagnosis, classification, and efficacy of AA were based on the criteria of Camitta et al. ${ }^{5,6}$ Additionally, the patients underwent bone marrow biopsies, chromosome karyotype analyses, and peripheral blood erythroid and myeloid CD55/CD59 testing in order to exclude low-proliferative myelodysplastic syndrome and paroxysmal nocturnal hemoglobinuria.

\section{Statistical methods}

The SPSS13.0 software package was employed for statistical analysis. Categorical data were summarized as frequencies. Normally distributed continuous data were summarized as means with corresponding standard deviations. Nonnormally distributed continuous data were summarized as medians with the corresponding range. The categorical data of the baseline feature and efficacy in the two groups were compared using $\chi^{2}$ test or Fisher's exact test, and continuous data were compared using Student's $t$-test. A $P$-value less than 0.05 was considered statistically significant.

\section{Ethics approval}

The study was approved by the Ethics Committee of the 100th Hospital of People's Liberation Army. Informed written consent was obtained from all patients or their relatives in accordance with the Declaration of Helsinki.

\section{Results}

\section{Clinical characteristics}

\section{SNHAA patients}

The SNHAA patients had a previous history of conspicuous hepatitis prior to the onset of AA. All the virologic tests were negative, and the prior hepatitis was mainly manifested as jaundice and elevated transaminase. AA did not occur until the transaminase was close to or completely normal after treatments such as liver protection and transaminase reduction. The median time from AA to hepatitis was 4 months. In nine cases, AA had an abrupt onset with rapid deterioration into SAA, among which there were six cases of very severe AA (Table 1). In the HBVAA group, there were 12 cases of the SAA type, and there was no statistically significant difference in proportion of SAA type between the two groups $(P=0.065)$. No statistical significance was observed in the hemoglobin or platelet count between the two groups at the time of AA onset $(P>0.05)$. In the HBVAA group, no patient had significant liver damage, and ten patients even denied that they had been infected with HBV. Twelve patients with known HBV infection had a median time from infection to AA diagnosis of 92 (22-144) months, with a distinctly long interval from hepatitis to AA onset when compared to the patients in the SNHAA group $(P=0.001)$. At AA diagnosis, white blood cell and absolute neutrophil count were much lower in the SNHAA group than in the HBVAA group

Table I Baseline data of the two groups at AA diagnosis

\begin{tabular}{|c|c|c|c|}
\hline & SNHAA $(n=10)$ & HBVAA $(n=22)$ & $P$ \\
\hline Sex (male/female) & $8 / 2$ & $14 / 8$ & \\
\hline Median age (range in years) & $18(6-36)$ & $28(17-57)$ & 0.006 \\
\hline Median interval for diagnosis & $4(\mathrm{I}-8)$ & $92(22-144)$ & 0.001 \\
\hline \multicolumn{4}{|c|}{ from hepatitis to AA (range in months) } \\
\hline \multicolumn{4}{|c|}{ Type of AA } \\
\hline VSAA & 6 & 5 & 0.065 \\
\hline SAA & 3 & 7 & \\
\hline NSAA & 1 & 10 & \\
\hline WBC $\left(\times 10^{9} / L\right)(M \pm S D)$ & $0.80 \pm 0.37$ & $1.23 \pm 0.52$ & 0.026 \\
\hline ANC $\left(\times 10^{9} / L\right)(M \pm S D)$ & $0.26 \pm 0.16$ & $0.58 \pm 0.25$ & 0.0009 \\
\hline PLT $\left(\times 10^{9} / L\right)(M \pm S D)$ & $10.3 \pm 11.11$ & $15.6 \pm 12.30$ & 0.25 \\
\hline $\mathrm{HB}(\mathrm{g} / \mathrm{L})(\mathrm{M} \pm \mathrm{SD})$ & $69.2 \pm 13.88$ & $71.6 \pm 15.22$ & 0.67 \\
\hline \multicolumn{4}{|l|}{ Subtype of T-cell (\%) } \\
\hline $\mathrm{CD} 4^{+}$ & $23.35 \pm 6.65$ & $28.2 I \pm 7.52$ & 0.09 \\
\hline $\mathrm{CD}^{+}$ & $41.27 \pm 4.57$ & $42.23 \pm 5.42$ & 0.63 \\
\hline $\mathrm{CD}^{+} / \mathrm{CD}^{+}{ }^{+}$ & $0.58 \pm 0.21$ & $0.78 \pm 0.31$ & 0.07 \\
\hline Hematopoietic cells in BM (\%) & $20.6 \pm 2.4 I$ & $23.6 \pm 3.87$ & 0.03 \\
\hline
\end{tabular}

Abbreviations: AA, aplastic anemia; ANC, absolute neutrophil count; BM, bone marrow; HB, hemoglobin; HBVAA, hepatitis B virus infection complicating aplastic anemia; NSAA, non-severe aplastic anemia; PLT, platelet; SAA, severe aplastic anemia; SNHAA, seronegative hepatitis aplastic anemia; VSAA, very severe aplastic anemia; WBC, white blood cell. 
$\left(0.8 \times 10^{9} / \mathrm{L}\right.$ versus $1.23 \times 10^{9} / \mathrm{L}, P=0.026$ and $0.26 \times 10^{9} / \mathrm{L}$ versus $0.58 \times 10^{9} / \mathrm{L}, P=0.0009$, respectively), and residual hematopoietic tissues were significantly reduced $(20.6 \%$ versus $23.6 \%, P=0.03$ ). Additionally, there was a trend toward a reduction in $\mathrm{CD}^{+} \mathrm{T}$-cell subsets $(23.35 \%$ versus $28.21 \%$, $P=0.09)$ and $\mathrm{CD} 4 / \mathrm{CD} 8$ ratio $(0.58$ versus $0.78, P=0.07)$ in the patients of the SNHAA group, but with respect to the two groups there was no significant difference in $\mathrm{CD} 8^{+} \mathrm{T}$-cells ( $41.27 \%$ versus $42.23 \%, P=0.63$ ) (Tables 1 and 2 ).

\section{Efficacy and recurrence}

The patients in the SNHAA group had a response to IST 2 months faster than that in the HBVAA group (2.5 months versus 4.5 months, $P=0.015$ ). The response rate and complete remission in the SNHAA group was $80 \%$ and $60 \%$, respectively, while the response rate in the HBVAA group was $81.8 \%$ and $10(45.5 \%)$ cases were cured, showing no significant difference in efficacy between the two groups $(P=0.48)$. Four patients (two in each group) died, with one death being attributable to uncontrollable infection and the other three due to intracranial hemorrhage (two of which were complicated by severe infection), showing no significant difference in the mortality rate between the two groups $(P=0.58)$. In the SNHAA group, there was not one case of recurrence, while in the HBVAA group there were two cases of recurrence, showing no significant difference in the recurrence rate between the two groups $(P=0.56)$ (Tables 3 and 4).

\section{Adverse reactions}

Common adverse effects such as fever, rash, and thrombocytopenia were observed in all the patients during the course of treatment with ALG. There was one case of hemolytic anemia in each group, and in the HBVAA group there was one case of serum disease. Common side effects observed in the patients receiving long-term oral CsA included hirsutism, gastrointestinal reactions, hypertension, hand tremors, gingival hyperplasia, etc, in both groups, but no difference was found. Neither significant liver injury nor fulminant hepatitis B was observed in any of the patients during the follow-ups.

\section{Discussion}

HAA usually occurs at 2-3 months (but not more than a year) after an unexplained hepatitis. ${ }^{1,2,7}$ It has an abrupt onset and is usually manifested as SAA. It is common in children and young male patients. ${ }^{1}$ In the West it is found in $2 \%-5 \%$ of patients with AA, but in Asia the proportion ranges up to $10 \%{ }^{8}$ HAA has abnormal T-cell subsets but shows good response to IST. ${ }^{1,2}$ Over a 17 -year period, Locasciulli et al ${ }^{8}$

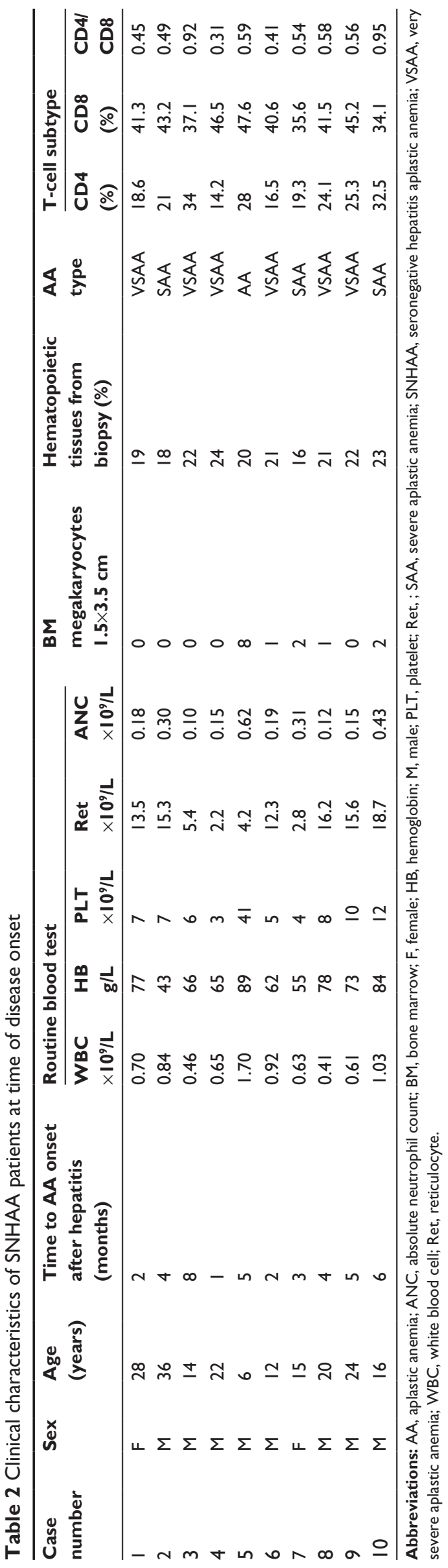


Table 3 Efficacy of IST and complications in SNHAA patients

\begin{tabular}{|c|c|c|c|c|c|c|c|c|}
\hline $\begin{array}{l}\text { Case } \\
\text { number }\end{array}$ & Sex & $\begin{array}{l}\text { Age } \\
\text { (years) }\end{array}$ & $\begin{array}{l}\text { AST } \\
\text { (U/L) }\end{array}$ & $\begin{array}{l}\text { Treatment } \\
\text { regimen }\end{array}$ & $\begin{array}{l}\text { Length of } \\
\text { follow-up } \\
\text { (months) }\end{array}$ & Outcome & $\begin{array}{l}\text { Complications or } \\
\text { causes of death }\end{array}$ & Recurrence \\
\hline $\mathrm{I}$ & $\mathrm{F}$ & 28 & $12-38$ & IST & 0.7 & Died & $\begin{array}{l}\text { Lung infection/ } \\
\text { intracranial hemorrhage }\end{array}$ & - \\
\hline 2 & $M$ & 36 & $\mathrm{II}-24$ & IST & 36 & Cured & No & No \\
\hline 3 & M & 14 & $19-29$ & IST & 0.6 & Died & Intracranial hemorrhage & - \\
\hline 4 & $M$ & 22 & $15-56$ & IST & 24 & Cured & Acute hemolysis & No \\
\hline 5 & $M$ & 6 & $11-32$ & CSA & 120 & Cured & No & No \\
\hline 6 & $M$ & 12 & $13-35$ & IST & 34 & Relieved & Pneumonia & No \\
\hline 7 & $\mathrm{~F}$ & 15 & $|0-4|$ & IST & 103 & Cured & No & No \\
\hline 8 & M & 20 & $9-38$ & IST & 19 & Cured & Pneumonia & No \\
\hline 9 & M & 24 & $8-45$ & IST & 77 & Cured & Bloodstream infection & No \\
\hline 10 & $M$ & 16 & $17-37$ & IST & 49 & Relieved & No & No \\
\hline
\end{tabular}

Abbreviations: AST, aspartate transaminase; CSA, cyclosporine A; F, female; IST, immunosuppressive therapy; M, male; SNHAA, seronegative hepatitis aplastic anemia.

conducted a study on a total of 3,916 patients with AA in Europe; these included 214 cases of HAA, accounting for $5.4 \%$ of all AA cases. The patients developed AA at an average age of 15 years, with the male to female ratio of 2.1:1. Only $14(6 \%)$ patients were coinfected with hepatitis virus. The 10 -year overall survival rate was $69 \%$ in the IST treatment group and $70 \%$ in hematopoietic stem cell transplantation group, which showed no significant difference between the two groups. Cox multivariate analysis revealed that age $\geq 20$ years and treatment delay $\geq 26$ days after diagnosis were the two adverse factors affecting longterm survival. In our study, this viewpoint is supported by the clinical characteristics of patients with SNHAA. This current study demonstrates results that are similar to the European studies with respect to the incidence and type of AA, the hepatitis etiological parameters, the interval from the acute episode of hepatitis to AA onset, the proportions of the patients' ages and sexes, and the efficacy of IST. Patients with SNHAA tend to have severe abnormalities of T-cell subsets, but they show a quicker response to IST. However, patients with HBVAA generally do not have the symptoms of acute hepatitis, with median interval from HBV infection to AA onset of 92 months, which is far longer than the 1-year period specified as a presumptive interval in the classical definition. ${ }^{1,8}$ Additionally, there is a high rate (up to $10 \%$ ) of HBV infection in The People's Republic of China's population, and HBVAA cases make up only $6.62 \%$ in all AA patients in the current study, and the percentage is well below than $10 \% \mathrm{HBV}$ infection rate in the common population of the People's Republic of China. Therefore, we believe it appropriate to define patients with SNHAA as having HAA. However, in the HBVAA group, patients have a much longer interval from hepatitis to AA onset than that specified in the criteria for HAA diagnosis, and these cases have a lower HBV infection proportion, thus indicating that HBV infection may not be the causative agent of AA.

The cause of hepatitis in HAA patients has not been fully determined. Early studies suggest that it should be associated with infection of viruses, including various hepatitis viruses (A-G type), HIV, EBV, CMV, HPV B19, blood transfusionassociated virus, and enteric cytopathogenic human orphan virus. ${ }^{2}$ Most of the findings in domestic studies show that it is associated with hepatitis virus infection. However, recent studies suggest an insufficiency of etiological evidence to support the association of hepatitis virus with AA, and most studies believe that the cause is unknown and that all relevant serologic markers of hepatitis virus are negative. ${ }^{9-11}$ These patients demonstrate good response to IST, and no case developed fulminant viral infection. ${ }^{1,8}$ Additionally, these patients have abnormal T-cell subsets. ${ }^{1}$ It is speculated that hepatitis

Table 4 Comparison of efficacy between the two groups

\begin{tabular}{|c|c|c|c|c|c|c|}
\hline \multirow[t]{2}{*}{ Group (n) } & \multicolumn{3}{|c|}{ Efficacy n (\%) } & \multirow{2}{*}{$\begin{array}{l}\text { Time to response } \\
\text { (months }[\mathrm{M} \pm \mathrm{SD}] \text { ) }\end{array}$} & \multirow{2}{*}{$\begin{array}{l}\text { Recurrence } \\
\text { n (\%) }\end{array}$} & \multirow{2}{*}{$\begin{array}{l}\text { Death } \\
\text { n (\%) }\end{array}$} \\
\hline & CR & PR & No response & & & \\
\hline SNHAA $(n=10)$ & $6(60.0)$ & $2(20.0)$ & 0 & $2.5 \pm 1.2$ & $0(0)$ & $2(20.0)$ \\
\hline HBVAA $(n=22)$ & $10(45.5)$ & $8(36.4)$ & $2(9.1)$ & $4.5 \pm 2.3$ & $2(11.1)$ & $2(9.1)$ \\
\hline$P$ & 0.48 & & & 0.015 & 0.56 & 0.58 \\
\hline
\end{tabular}

Abbreviations: CR, complete remission; HBVAA, hepatitis B virus infection complicating aplastic anemia; PR, partial remission; SNHAA, seronegative hepatitis aplastic anemia. 
and AA are mediated by autoimmune attacks. Previous studies have shown that the soluble liver antigen-specific IFN- $\gamma$ level is significantly higher in patients with autoimmune hepatitis than in patients with HBV infection, suggesting that $\mathrm{T}$-cell abnormality in patients with autoimmune hepatitis may play an important role in developing AA and incurring liver damage. ${ }^{12,13}$

IST and hematopoietic stem cell transplantation continue as mainstays in the treatment of SAA, and they have the similar effective rate of approximately $70 \% .^{1,2,7}$ However, given the policy on family planning it is highly unlikely to have a sibling donor in a patient under the age of 30, so in The People's Republic of China IST is a more realistic choice for the patient with SAA. Previous results from domestic and foreign studies revealed poor prognoses for patients with HAA. ${ }^{14-16}$ Today, thanks to early IST intervention, more efficient antibiotics, adequate blood-component transfusion, and hematopoietic cytokine therapy, the efficacy of HAA treatment is significantly improved and it is nearly the same for common SAA.,2,17 Moreover, the results of our study suggest that the early administration of IST can achieve a similar efficacy for patients with HAA or HBV infection complicating AA. Most of the early deaths have been associated with intracranial hemorrhage resulting from the insufficient infusion of platelets, whereas the lower recurrence rate may be attributed to the longer duration of oral CsA.

The change in liver function among HAA patients after IST administration is an issue of concern to clinicians. However, most international research studies have confirmed that IST does not lead to liver damage or fulminant HBV infection. Osugi et $\mathrm{al}^{17}$ even found that IST in severe HAA patients did not increase the occurrence of liver injury but instead significantly reduced the liver transaminase level and consequently improved the liver function. Cytotoxic T-cells may mediate liver damage while IST can reduce cytotoxic T-cells and restore liver function, whereby early IST can serve a dual role and dramatically improve the patient's prognosis. The patients with positive HBsAg or a small number of patients with negative HBsAg but positive $\mathrm{HBcAb}$ and hepatitis $\mathrm{B}$ e antibody may show increased HBV-DNA replication and elevated transaminase level after receiving IST. ${ }^{18}$ Therefore, prophylactic antiviral therapy can be given to patients with HBV infection who receive IST in order to limit the resurgence of HBV. Generally, drugs with low nephrotoxicity, such as lamivudine, telbivudine, and entecavir, are selected as the means to limit resurgence. ${ }^{19}$ Moreover, the results of our study indicate that no patient had developed aggravation of liver damage other than fulminant hepatitis viral infection. Among the HBV infection patients with AA who are receiving IST, 13 patients with high HBV DNA copies also have received lamivudine or entecavir antiviral therapy. The copies of HBV DNA decreased significantly after the treatment, confirming that IST in combination with antiviral drugs is beneficial to patients with hepatitis B.

\section{Conclusion}

In conclusion, the prevalence of seronegative HAA is $3.01 \%$. HAA is different from HBV infection complicating AA, which often occurs during the recovery period of hepatitis with an abrupt onset, and it responds more readily to IST than does HBV infection complicating AA. Neither hepatitis prior to AA nor hepatitis B infection affects the efficacy of IST. However, HBV infection may not be the causative agent of AA. Nevertheless, further study is needed to confirm and clarify these findings.

\section{Acknowledgment}

This work was funded by military medical research funds (10MA015, 12MA021, 13ZD10).

\section{Disclosure}

The authors report no conflicts of interest in this work.

\section{References}

1. Brown KE, Tisdale J, Barrett AJ, Dunbar CE, Young NS. Hepatitisassociated aplastic anemia. $N$ Engl J Med. 1997;336:1059-1064.

2. Rauff B, Idrees M, Shah SAR, et al. Hepatitis Associated Aplastic Anemia: A review. Virol J. 2011;8:87. Available from: http://www. virologyj.com/content/8/1/87. Accessed August 23, 2014.

3. Custer B, Sullivan SD, Hazlet TK, Iloeje U, Veenstra DL, Kowdley KV. Global epidemiology of hepatitis B virus. J Clin Gastroenterol. 2004; 38:S158-S168.

4. Liu J, Fan D. Hepatitis B in China. Lancet. 2007;369(9573):1582-1583.

5. Camitta BM, Thomas ED, Nathan DG, et al. A prospective study of androgens and bone marrow transplantation for treatment of severe aplastic anemia. Blood. 1979;53:504-514.

6. Camitta BM, Thomas ED, Nathan DG, et al. Severe aplastic anemia: a prospective study of the effect of early marrow transplantation on acute mortality. Blood. 1976;48:63-70.

7. Hagler L, Pastore RA, Bergin JJ, Wrensch MR. Aplastic anemia following viral hepatitis: report of two fatal cases and literature review. Medicine (Baltimore). 1975;54:139-164.

8. Locasciulli A, Bacigalupo A, Bruno B, et al. Hepatitis-associated aplastic anaemia: epidemiology and treatment results obtained in Europe. A report of The EBMT aplastic anaemia working party. Br J Haematol. 2010;149:890-895.

9. Pol S, Driss F, Devergie A, Brechot C, Berthelot P, Gluckman E. Is hepatitis $\mathrm{C}$ virus involved in hepatitis-associated aplastic anemia? Ann Intern Med. 1990;113:435-437.

10. Hibbs JR, Frickhofen N, Rosenfeld SJ, et al. Aplastic anemia and viral hepatitis. Non-A, Non-B, Non-C? JAMA. 1992;267:2051-2054.

11. Pant A, Kale P, Harjai K, Shah M, Pathare AV. Non-A non-B hepatitis induced aplastic anemia. J Postgrad Med. 1992;38:85-86. 
12. Zhao Y, Zhang Y, Liu YM, et al. Identification of T cell epitopes on soluble liver antigen in Chinese patients with auto-immune hepatitis Liver Int. 2011;31:721-729.

13. Grant CR, Liberal R, Holder BS, et al. Dysfunctional CD39(POS) regulatory $\mathrm{T}$ cells and aberrant control of T-helper type 17 cells in autoimmune hepatitis. Hepatology. 2014;59:1007-1015.

14. Najean Y, Pecking A. Prognostic factors in acquired aplastic anemia. A study of 352 cases. Am J Med. 1979;67:564-571.

15. de Planque MM, Kluin-Nelemans HC, van Krieken HJ, et al. Evolution of acquired severe aplastic anemia to myelodisplasia and subsequent leukemia in adults. Br J Haematol. 1988;70:55-62.
16. Tu MF, Shao ZH, Liu H, et al. [The clinical features of hepatitis associated aplastic anemia.] Zhonghua Xue Ye Xue Za Zhi. 2005;26:239-242. Chinese.

17. Osugi Y, Yagasaki H, Sako M, et al. Antithymocyte globulin and cyclosporine for treatment of 44 children with hepatitis associated aplastic anemia. Haematologica. 2007;92:1687-1690.

18. Dai MS, Kao WY, Shyu RY, Chao TY. Restoration of immunity and reactivation of hepatitis B virus after immunosuppressive therapy in a patient with severe aplastic anaemia. J Viral Hepat. 2004;11:283-285.

19. Lok AS, McMahon BJ. Chronic hepatitis B. Hepatology. 2007;45 507-539.

\section{Publish your work in this journal}

Drug Design, Development and Therapy is an international, peerreviewed open-access journal that spans the spectrum of drug design and development through to clinical applications. Clinical outcomes, patient safety, and programs for the development and effective, safe, and sustained use of medicines are a feature of the journal, which has also been accepted for indexing on PubMed Central. The manuscript management system is completely online and includes a very quick and fair peer-review system, which is all easy to use. Visit http://www.dovepress.com/testimonials.php to read real quotes from published authors.

Submit your manuscript here: http://www.dovepress.com/drug-design-development-and-therapy-journal 